\title{
APREENSÃO DE TÓPICOS EM ÉTICA MÉDICA NO ENSINO-APRENDIZAGEM DE PEQUENOS GRUPOS. COMPARANDO A APRENDIZAGEM BASEADA EM PROBLEMAS COM $O$ MODELO TRADICIONAL
}

\author{
Eliandro José Gutierres figueira, Everton Cazzo, Paula Tuma, \\ Carlos Rodrigues da Silva Filho*, Lucieni de Oliveira Conterno \\ Trabalho realizado na Faculdade de Medicina de Marília, SP.
}

RESUMO - OBJETIVo. 0 presente estudo tem como objetivo avaliar 0 ensino de ética médica durante 0 curso de medicina e se houve mudança na aquisição de conhecimentos em ética médica com 0 redirecionamento do modelo pedagógico da Faculdade de Medicina de Marilia.

Métodos. Foi realizado estudo prospectivo e analítico, baseado na aplicação de questionários sobre temas gerais em Ética, em dois períodos distintos.

Resultados. Observou-se não haver diferenças significantes entre a aquisição de conhecimentos entre os dois métodos. Verificouse que os alunos de anos mais próximos do término do curso apresentaram desempenho significativamente melhor que os ingressantes no curso. Os tópicos que apresentaram menor índice de acerto compreendiam o sigilo médico, o consentimento do responsável, a autonomia do paciente, a prescrição médica, 0 prontuário médico e o corporativismo em relação ao erro médico.

Conclusão. A variável mais importante não foi o modelo pedagógico e sim 0 tempo de exposição ao tema. 0 modelo $A B P$ dá chance de distribuir $\mathrm{O}$ tema em vários módulos $\mathrm{e}$ tutorias durante o curso médico ajudando a acelerar o processo de aquisição de conhecimentos em ética médica. Conclui-se que é necessário uma revitalização do ensino da Ética Médica em nossa instituição, visando a uma maior integração com a conjuntura socioeconômica de nosso país.

Unitermos: Ética Médica. Ensino. Questionário.

\section{INTRODUÇÃO}

Quanto mais nos adentramos no território da ética percebemos a presença de interrelações e a pouca valia de um pensamento linear, que partisse de determinados axiomas e fosse deduzindo o que deve ser feito em situações particulares!

Aliás, como deve ser definido o termo ética". Ética é um conjunto de normas que regulamentam o comportamento de um grupo particular de pessoas, como, por exemplo, advogados, médicos, psicólogos, psicanalistas etc., diferenciando-se da moral devido apenas ao conteúdo menos especifico da última, que representaria a cultura de uma nação, uma religião ou época.

Outro enfoque possível para se definir "ética" é proposto por Cohen e Segre, segundo o qual a ética se fundamentaria em trêspré-requisitos básicos: I) consciência

*Correspondência

Rua José Camarinha, 467 - CEP: 17516-220

Marília - SP - Tel.: (17) 516220

E-mail: silvacr@famema.br (percepção dos conflitos entre emoção e razão); 2) autonomia (condição de se posicionar entre a emoção e a razão); 3) coerência².

Diferencia-se da moral, segundo esta visão, considerada mais adequada pelos autores, pela existência do livre arbítrio associado à coerência, em oposição à inquestionabilidade dos princípios morais clássicos².

Por outro lado, a Ética Profissional ou Deontologia caracteriza-se como conjunto de normas ou princípios que têm por fim orientar as relações profissionais entre pares, destes com seus clientes, com sua equipe de trabalho, com as instituições a que servem, entre outros. Como a sua margem de aplicação é limitada ao círculo profissional, faz com que estas normas sejam mais específicas e objetivas, gerando o advento dos Códigos de Ética elaborados por associações de classe, como, por exemplo, o Código de Ética Médica Brasileiro, constituído a partir de discussões entre os profissionais ligados à área e a sociedade e suas demandas, e homologado pelo Conselho Federal de Medicina (CFM).

Costa já dizia, em 1987, que a grande maioria dos médicos brasileiros não conhecia o conteúdo de seu Código de Ética Médica, e que a menor parcela de culpa por esta situação seria dos próprios médicos, pois o ensino de ética profissional nos cursos de graduação estava longe do mínimo necessário? ${ }^{3}$.

Nos cursos de Medicina, o ensino da Ética, na maioria das vezes, está centrado nos temas escolhidos pelo docente, sem levar em conta as ansiedades, os pontos de vista e os interesses dos alunos; com freqüência, os temas estão dissociados dos assuntos e dos dilemas éticos que os mesmos estão vivenciando, e, quase sempre, a abordagem dos tópicos é feita primordialmente pelo ângulo da Deontologia, sendo esta enfocada como a ciência dos deveres, na visão de Jeremy Bentham. Desse modo, a reflexão critica sobre os valores não é estimulada ${ }^{4}$.

Na Faculdade de Medicina de Marilia, em 1997, houve a implantação de um novo modelo de ensino-aprendizagem, com uma reestruturação curricular e uma revisão dos conceitos didáticos outrora vigentes, com a introdução do Aprendizado Baseado em Problemas (ABP, ou PBL - Problem Based Learning). 
Deste modo, o aprendizado passou a se dar através de discussões em pequenos grupos, coordenados por docentes (tutores) que na elaboração dos casos são estimulados a incluir nestes aspectos da ética aliados a atividades práticas referentes ao assunto abordado, com maior flexibilidade na organização dos tópicos. Essas discussões são denominadas tutorias. Assim, espera-se que os alunos adquiram conhecimentos acerca da Ética Médica ao abordar problemas ou situações onde haja conflitos de natureza ética, elaborados por docentes das diversas disciplinas e discutidos nas tutorias.

O presente estudo tem por objetivos: analisar a existência ou não de diferenças significantes entre o aprendizado de tópicos de Etica Médica e Deontologia Médica entre os diferentes modelos pedagógicos presentes em nossa instituição e avaliar o nível médio de conhecimento em Ética Médica entre os diferentes anos de graduação e corpo docente.

\section{Métodos}

Este estudo é do tipo observacional analítico, baseado na coleta prospectiva de dados referentes a dois questionários (anexos 3 e 4). Eles são compostos por 25 questões de Ética Médica cada, sendo que cada questão em ambos os questionários avalia um mesmo tópico do Código de Ética, ou seja, eles se equivalem e examinam o mesmo conceito, enunciados de forma ligeiramente diferente.

Quando o projeto de pesquisa foi iniciado, 200I, havia apenas uma turma (cerca de 80 alunos) no ensino tradicional e cinco turmas (cerca de 400 alunos) no ABP, iniciando-se assim a elaboração do questionário inicial. Ele foi confeccionado após revisão bibliográfica extensa e discussão com docentes envolvidos com a área, onde foram detectados os principais temas e dilemas éticos vivenciados na prática médica ${ }^{5-13}$. Foi realizado projeto piloto envolvendo alunos do $3^{\circ}$ ano do curso de Medicina da Universidade Estadual de Londrina, sendo observadas então potenciais fragilidades do questionário modelo, propiciando a elaboração do questionário final. O segundo questionário foi constituído tendo por base o primeiro, respeitando-se os tópicos abordados, inclusive mantendo-se a ordem e a idéia original das questões.

A população estudada abrangeu amostras dos corpos discente e docente da Faculdade

\begin{tabular}{|c|c|c|}
\hline \multicolumn{3}{|c|}{ Tabela I - Caracterização sociodemográfica da população analisada } \\
\hline & Questionário I - N (\%) & Questionário 2-N(\%) \\
\hline \multicolumn{2}{|r|}{ 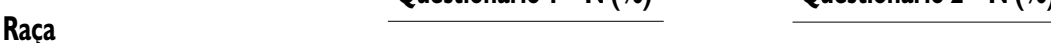 } & \\
\hline $\begin{array}{l}\text { Branca } \\
\text { Negra }\end{array}$ & $\begin{array}{c}102(18,3) \\
5(2,4)\end{array}$ & $\begin{array}{c}89(8 /, 3) \\
(1,0)\end{array}$ \\
\hline Outra & $19(9,2)$ & $8(7,8)$ \\
\hline Não respondeu & $21(10,1)$ & $2(2,0)$ \\
\hline \multicolumn{3}{|l|}{ Idade } \\
\hline$<18$ anos & $5(2,4)$ & $2(2,0)$ \\
\hline$|8-2|$ anos & $66(31,9)$ & $17(16,7)$ \\
\hline $22-25$ anos & $88(42,5)$ & $52(51,0)$ \\
\hline$>25$ anos & $42(20,3)$ & $31(30,4)$ \\
\hline Não respondeu & $6(2,9)$ & $0(0)$ \\
\hline \multicolumn{3}{|l|}{ Sexo } \\
\hline Masculino & $97(46,9)$ & $44(43,1)$ \\
\hline Feminino & $100(48,3)$ & $58(56,9)$ \\
\hline Não respondeu & $10(4,8)$ & $0(0)$ \\
\hline \multicolumn{3}{|l|}{ Religião } \\
\hline Católica & $130(62,8)$ & $55(53,9)$ \\
\hline Evangélica & $9(4,3)$ & $10(9,8)$ \\
\hline Outra & $27(13,0)$ & $14(13,7)$ \\
\hline Não possuil & $15(7,2)$ & $11(10,8)$ \\
\hline Não respondeu & $26(12,6)$ & $12(11,8)$ \\
\hline
\end{tabular}

de Medicina de Marília. Os questionários foram aplicados nas sessões de tutoria do $1^{\circ}$ ao $4^{\circ}$ ano do curso médico, e nas atividades curriculares dos demais alunos e docentes. Os anos de graduação foram numerados de 1 a 6 , e os docentes como 7. Na aplicação subseqüente, foi mantida a numeração original, sendo os residentes (RI) foram colocados no grupo 6 da segunda fase. Cabe ressaltar que em nossa instituição, $06^{\circ}$ ano foi o último ano de graduação onde a método de aprendizado era o modelo tradicional.

Conforme a resolução 196, de 10 de outubro de 1996, do Conselho Nacional de Saúde, foi elaborado termo de consentimento, que era preenchido por todos os participantes do estudo, sem necessidade de identificação nominal, tanto no termo quanto no questionário.

A coleta de dados foi realizada em dois períodos, tendo sido o primeiro questionário aplicado entre os meses de julho e novembro de 2001, e o segundo entre os meses de fevereiro a maio de 2002. Foram eliminados os questionários não-preenchidos e aqueles que não entregaram o termo de consentimento em anexo.

Os dados foram, então, analisados através do pacote estatístico STATA, tendo sido calculadas as variáveis de associação e sua análise estatística, tendo sido considerados significativas as diferenças com nível de significância menor que 0,05 . Ulteriormente, os resultados foram agrupados em tabelas e gráficos.

\section{Resultados}

A população estudada encontra-se descrita na Tabela I (Anexo I). O índice de acertos dos questionários I e 2 por ano de graduação estão demonstrados na Tabela 2 (Anexo I) e no Gráfico I (Anexo 2). Nota-se que houve evolução no percentual em todos os grupos, exceto no $2^{\circ}$ ano de graduação, possivelmente devido à baixa adesão a ambos os questionários.

Como podemos observar na Tabela 3 (Anexo I), houve diferença estatisticamente significante na média de acertos em ambos os questionários quando comparamos os alunos do $4^{\circ}$ ao $6^{\circ}$ ano e docentes aos alunos do $1^{\circ}$ ano. Também foi observada diferença significativa entre a performance do $3^{\circ}$ e do $5^{\circ}$ ano, com vantagem para o último, possivelmente em decorrência da diferença de adesão entre os questionários.

A Tabela 4 (Anexo I) mostra o percentual de acertos individuais de cada tópico, discriminado segundo o artigo do Código de Ética que 0 regulamenta, e a variação entre os acertos entre as duas fases do estudo. 


\begin{tabular}{|c|c|c|c|c|c|}
\hline & Questionário I & $\mathbf{N}$ & Questionário 2 & $\mathbf{N}$ & Variação (p) \\
\hline $1^{\circ}$ & 13,97 & 42 & 18,25 & 8 & $<0,00 \mid$ \\
\hline $2^{\circ}$ & 15,75 & 20 & 17,44 & 9 & 0,119 \\
\hline $3^{\circ}$ & 15,48 & 33 & 17,56 & 16 & 0,014 \\
\hline $4^{\circ}$ & 15,08 & 24 & 20,05 & 17 & $<0,001$ \\
\hline $5^{\circ}$ & 16,66 & 27 & 19,05 & 34 & 0,001 \\
\hline $6^{\circ}$ & 16,77 & 40 & 18,54 & 11 & 0,050 \\
\hline Docentes & 16,04 & 21 & $|9,7|$ & 7 & 0,001 \\
\hline
\end{tabular}

Figura I - Percentual de acertos por ano de graduação nos questionários

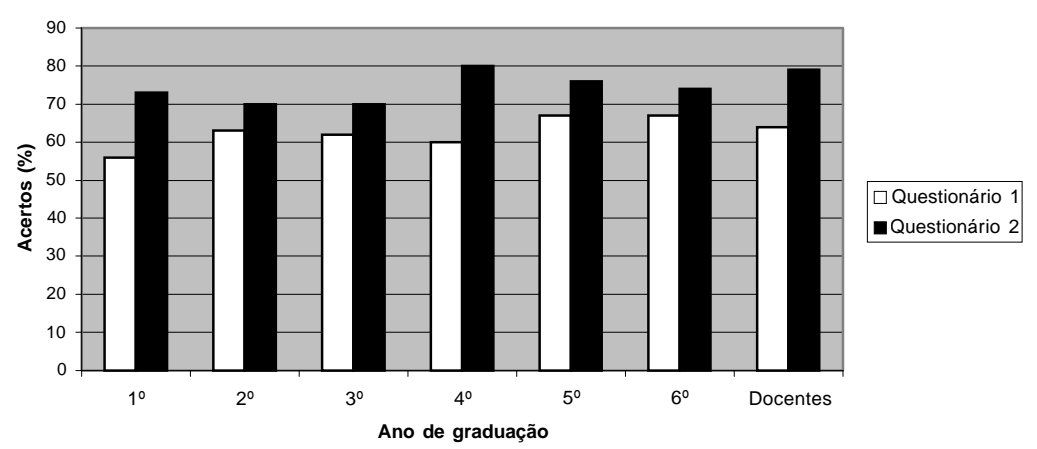

Tabela 3 - Diferença estatística entre a média de acertos nos questionários aplicados entre os anos de graduação analisados e corpo docente (valores de $\mathrm{p}$ )

\begin{tabular}{|c|c|c|c|c|c|c|c|}
\hline & $1^{\circ}$ & $2^{\circ}$ & $3^{\circ}$ & $4^{\circ}$ & $5^{\circ}$ & $6^{\circ}$ & Docentes \\
\hline $\begin{array}{l}10 \\
2^{\circ} \\
3^{\circ} \\
4^{\circ} \\
5^{\circ} \\
6^{\circ} \\
\text { Docentes }\end{array}$ & $\begin{array}{c}X \\
0,351 \\
0,205 \\
0,001 \\
<0,001 \\
<0,001 \\
0,016\end{array}$ & $\begin{array}{c}\overline{0,351} \\
X \\
1,000 \\
1,000 \\
0,174 \\
1,000 \\
1,000\end{array}$ & $\begin{array}{c}\overline{0,205} \\
1,000 \\
X \\
1,000 \\
0,021 \\
1,000 \\
1,000\end{array}$ & $\begin{array}{c}0,001 \\
1,000 \\
1,000 \\
X \\
1,000 \\
1,000 \\
1,000\end{array}$ & $\begin{array}{c}<0,001 \\
0,174 \\
0,021 \\
1,000 \\
X \\
1,000 \\
1,000\end{array}$ & $\begin{array}{c}<0,001 \\
1,000 \\
1,000 \\
1,000 \\
1,000 \\
X \\
1,000\end{array}$ & $\begin{array}{c}0,016 \\
1,000 \\
1,000 \\
1,000 \\
1,000 \\
1,000 \\
X\end{array}$ \\
\hline
\end{tabular}

Como pode ser observado na Tabela 5 (Anexo I), não houve diferença estatisticamente significante entre o conhecimento sobre os tópicos de Ética Médica abordados em ambos os questionários, comparando-se os grupos de alunos provenientes do ABP aos provenientes do modelo tradicional de ensino.

Pode-se observar nos Gráficos 2 e 3 (Anexo 2), os questionários foram aprovados pela população avaliada.

\section{Discussão}

O nível de conhecimento nos tópicos de Ética Médica abordados pelos questionários bros da comunidade acadêmica há mais tempo envolvido e exposto ao tema.

$\mathrm{Na}$ comparação entre os modelos de ensino, verificou-se uma diferença em favor do grupo remanescente do currículo tradicional, porém sem que a mesma fosse estatisticamente significante. Notem que foram comparados os alunos do grupo 6 contra todos os outros grupos compostos por acadêmicos. Isto reforça a hipótese de que o tempo de exposição e o contato com o tema durante o curso médico possivelmente apresentam maior influência na aquisição de conhecimentos em Ética Médica do que o método pelo qual estes temas são abordados.

Verificou-se melhora estatisticamente significativa no desempenho entre o primeiro e o segundo questionário em todos os grupos avaliados, exceto no $2^{\circ}$ e no $6^{\circ}$ ano. Acredita-se que tal melhora deva-se a diversos fatores, dos quais podemos destacar o próprio questionário, que suscitou discussões internas a respeito dos tópicos abordados e a existência de vários projetos na área de Ética Médica (outros sete) em nossa instituição, que colocaram o tema em grande evidência. Desse modo, durante a execução do projeto, criou-se um clima de apreensão de conhecimentos em Ética Médica. A inexistência de evolução significante no $2^{\circ}$ e $6^{\circ}$ anos provavelmente deveu-se à baixa amostragem na segunda fase.

Dentre os tópicos abordados, foi verificada diferença notável entre o percentual de acertos quando comparados os temas individualmente. Os tópicos que apresentaram menor índice de acerto foram: o acesso ao prontuário médico, o sigilo médico (tanto individual quanto em relação a risco), a autonomia do paciente, o consentimento do responsável, o corporativismo e a prescrição médica. Os demais tópicos apresentaram desempenho satisfatório. Os pontos controversos são discutidos individualmente a seguir, com base no Código de Ética Médica e literatura:

a) Prontuário Médico - Artigo 70, onde é ressaltado o acesso quase que irrestrito do paciente a seu prontuário. Existem controvérsias na literatura, havendo um autor que enfatiza ser o prontuário de autoria do médico, devendo este apenas informar ao paciente o que este julgar relevante ${ }^{14}$. Porém, tal fato não é corroborado por outros autores, que enfatizam ser o prontuário pertencente ao paciente ${ }^{3,15}$. 


\section{ANEXO - QUESTIONÁRIO I}

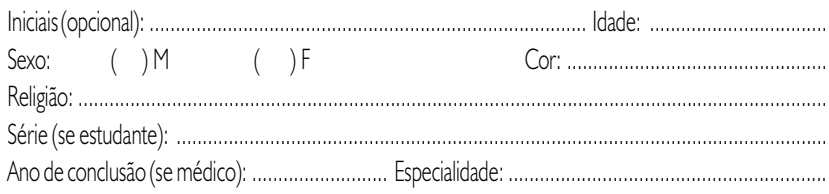

\section{QUESTÕES}

I. Você é docente de um ambulatório de Clínica, ao qual se encaminha um paciente com 78 anos, que necessitavafundoscopia e por quatro vezes já haviatentado marcar uma consultano setor de Oftalmologia doSUS, sem sucesso, devido à existência de um sistemairregular de privilégios no agendamento, mantido pelo funcionário responsável pelos agendamentos. Você, que tomou conhecimento acerca deste sistema: a) diz ao paciente que o mesmo não conseguirá consulta oftalmológica e explica o porquê, orientando-o a procurar outro serviço

b) denuncia o esquema irregular ao Conselho Regional de Medicina e à Secretaria de Saúde

c) procura o responsável pelos agendamentos e solicita que seu paciente seja atendido

d) orienta-o a procurar outro serviç̧, sem explicar o porquê

2. Paciente de 47 anos, coronariopata, está aguardando consulta no único ambulatório de cardiologia do SUS na cidade. O paciente encontra-se fumando enquanto aguarda sua vez. O cardiologista responsável, ao chegar e ver o paciente fumando, solicita que o mesmo procure outro médico, pois já dissera para que este não fumasse. Em sua opinião:

a) o cardiologista está certo, pois é seu direito recusar-se a atender o paciente

b) o cardiologista não está certo, pois é seu dever insistir, ainda que o paciente não colabore

c) o cardiologista está certo, pois o pacientenão segue tratamento corretamente, tornando-se oneroso ao sistemapúblico

d) o cardiologista não está certo, pois o médico nunca tem o direito de recusar-se a atender um paciente

3. Mãe, no $3^{\circ}$ dia de puerpério, solicita alta para seu filho, nascido pré-termo, ictérico e com imaturidade pulmonar, com indicação de internação e tratamento hospitalar. Você, que é o pediatra responsável:

a) libera a criança, pois a mãe tem direito total sobre seu filho

b) não libera a criança, comunica o caso à promotoria e solicita suspensão temporária do pátrio-poder da mãe

c) libera a criança e solicita retorno em UBS, no dia seguinte, em caráter urgente

d) não libera a criança e solicita ao Conselho Tutelar perda permanente da guarda por considerar a atitude materna muito lesiva à criança

4. Paciente internado solicità̀ enfermeira-chefe do setor que o deixe ver seu prontuário. A enfermeira deve: a) solicitar ao paciente que obtenha as informações que deseja com o médico responsável pelo seu caso b) solicitar ao paciente que peça autorização à direção do Hospital

c) disponibilizar o prontuário ao paciente

d) disponibilizar o prontuário após autorização do médico

5. Ao atender paciente em pré-natal de serviço público, esta lhe questiona sobre a possibilidade de que você, obstetra, faça o parto. Você só faz partos em um hospital particular. Qual seria a melhor conduta a ser tomada?

a) combinar o preço normalmente com a paciente, bem como as possíveis datas do parto

b) negar-se a fazer o parto sob qualquer forma

c) pedir que a mesma contate o hospital privado e avalie as possibilidades

d) entregar um cartão com endereço e telefone, pedindo-hhe que marque uma consulta em seu consultório particular para discutir melhor o assunto

6. Vocêtem dois tratamentos disponíveis para uma patologia crônica. Um é considerado padrão-ouro, mas éaltamente oneroso, e osegundo érazoavelmente satisfatório e apresenta custo sensivelmente mais baixo. Você considera correto:

a) explicar aos portadores detal patologia sobre os doistratamentos, e decidirem conjunto sobre qual opção deve ser utilizada

b) tratar apenas com o padrão-ouro, pois sempre se deve visar aos melhores resultados possíveis

c) prescrever o tratamento razoável no serviço público e o mais oneroso em consultório particular

d) indicar sempre o tratamento razoável devido ao principio ético de eqüidade
7. Estudante de Medicina procura um professor da faculdade e the entrega exame sorológico indicando HIV positivo, pede-the orientações acerca da AIDS e solicita que o mesmo não conte a ninguém sobre o ocorrido. O que o professor deve fazer?

a) orientar o aluno acerca dos cuidados com a imunossupressão e medicações que deve tomar e manter sigilo absoluto sobre o assunto

b) orientar o aluno e comunicar o fato a seus colegas médicos para melhor discussão do caso

c) orientar ao aluno, comunicar ofato ao diretor do hospital, àSecretaria da Saúde eao diretor dafaculdade, notificando assim a doença

d) orientar o aluno e fazer notificação da doença

8. Pacientede I4 anos, vitima de estupro encontra-se hospitalizadae pede para que omédico não diga à família o ocorrido. Qual a melhor conduta neste caso?

a) fazer a vontade da paciente, guardando sigilo sobre o caso e omitindo o fato

b) dizer a verdade para que a família ajude na recuperação da paciente

c) guardar sigilo sobre o assunto, orientando a familia a conversar calmamente com a paciente, para obter as informações que deseja, guardando assim sigilo sobre o assunto

d) dizer para a familila que fora outro motivo qualquer que motivou a hospitalização

9. Paciente em tratamento paratuberculose recusa-se a se afastar do emprego, continuando a conviver com as outras pessoas do seu oficicio. O que o médico deve fazer?

a) comunicar o médico da empresa em que o paciente trabalha e pedir para que conte ao patrão para que sejam tomadas medidas de providência

b) comunicar ofato ao Setor de Vigilância Sanitária

c) não deve fazer nada devido à lei do sigilo médico

d) respeitar a vontade do paciente, mas insistir para que ele se afaste do emprego

10. Às vésperas de um casamento, os noivos decidem fazer exames de sangue pré-nupciais e no resultado 0 noivo apresenta exame HIV positivo. Em conversa com o noivo, este lhe pede sigilo. O que deve o médico fazer a respeito?

a) nada, pois o resultado pode serfalso-positivo e poder-se-ia estar destruindo um casamento sem motivo concreto

b) solicitar novos exames de sangue dos dois para conferência, não contando nada à noiva c) comunicar o fato à noiva e orientá-la a levar em conta este fato em sua decisão de casar-se d) comunicar o fato à noiva mas tranqülilzá-la, pois o resultado dela é negativo

II. Paciente de 52 anos, portador de transtorno depressivo, revela suas intenções suicidas em consulta psiquiátrica, solicitando sigilo acerca de tal informação. Qual a melhor conduta? a) respeitar a vontade do paciente, mantendo sigilo sem alterar a sua prescrição b) revelar aos famillares sobre as intençōes do paciente c) interná-lo em Hospital Psiquíátrico, cogitando a hipótese de tratamento mais agressivo d) elevar a dose do antidepressivo e indicar psicoterapia mantendo sigilo

12. Em um pronto-socorro do Hospital Materno Infantil, chegam duas mulheres em processo de abortamento; durante rápida anamnese o médico de triagem descobre que em uma o abortamento foi por ela provocado e na outra se tratava de abortamento espontâneo. Ambas estão nas mesmas condiçōes hemodinâmicas e necessitam de tratamento cirúrgico, havendo apenas uma sala de cirurgia disponível. Qual das duas você operariaprimeiro?

a) a que está em abortamento espontâneo por questões morais e éticas

b) aquela que está em abortamento provocado devido ao maior risco de infecção

c) aquela que chegou primeiro

d) aquela cujo prognóstico geral melhore pela intervenção precoce.

13. Médico recém-formado abre consultório em cidade de pequeno porte e depara-se em certo instante com paciente em péssimas condições gerais necessitando de internação urgente. Na cidade só há um hospital privado do qual não conseguiu fazer parte do corpo clínico, sendo até aconselhado a mudar de cidade. O paciente quer que este médico cuide dele. Nesta situação, qual deveria ser a melhor conduta? a) encaminhar o paciente para o hospital privado, transferindo-o para outro médico e livrando-se assim da responsabilidade

b) levar o paciente para o hospital público mais próximo, mesmo que seja à média ou longa distância, permanecendo junto ao pacientenotransporte, mesmo comescassos recursos einternando-o sobre sua responsabilidade 
c) internar o paciente no hospital da cidade, ficando assim o paciente sob cuidados hospitalares e em sua responsabilidade, mesmo que haia atrito entre ele e os demais médicos do corpo clinico

d) levar o paciente ao hospital da cidade, explicar a situação a outro médico e abster-se da responsabilidade

14. Sr. X, 84 anos, portador de um câncer controlado, problemas cardíacos e hipertensão arterial sistêmica, teve vários episódios de angina e alguns infartos, tendo sido constatada uma obstrução importante em suas artérias. O paciente, semnenhumaalteraçãode sanidademental, pedequenãosetentenenhumaintervenção, sente que viveu o suficiente e gostaria de morrer em paz. Em determinado dia, sente muitas dores no peito e élevado ao hospital. Após ser avaliado, verifica-seaindicação de cateterismo. Omédicoéinformado dosfatos, e o Sr. X mantém seu pedido. O que pode/deve o médico que o atende naquele momento fazer? a) proceder ao cateterismo, mesmo contra avontade do SrXeconsiderando os efeitos adversos daintervenção b) conversar com o $\mathrm{Sr} X$ e convencê-lo de que isto pode lhe trazer benefício e, caso continue contrário, procurar o familiar e pedir sua autorização para o procedimento

c) respeitar a vontade do Sr. X. administrando medicações sintomáticas sem medidas invasivas, observandoevolução

d) recusar-se a continuar a atendê-lo caso não queira se submeter ao tratamento e transferi-lo para outrohospital

15. Criança de 10 anos, vitima de acidente com bicicletaétrazida ao pronto-socorro, éavaliada e hánecessidade de transfusão de sangue em regime de urgênncia. Afamilia é Testemunha de Jeováe senega ao procedimento de transfusão e alega ser melhor "fazer a vontade de Deus", ameaçando processar judicialmente médico e hospital caso seja feita transfusão. O que fazer neste caso?

a) aceitar a imposição da familia

b) avaliar o estado da paciente e fazer transfusão

c) solicitar atuaçãojudicicial imediatamente

d) comunicar imediatamente a direção do hospital

16. Paciente possuidor de convênio necessita de tratamento com determinadas medicações que o convênio não fornece. Qual a melhor conduta?

a) informar a necessidade daquelas medicações ao convênio

b) comunicar o fato ao paciente e realizar laudo demonstrando a necessidade das medicações, indicando que as solicitem ao convênio

c) comunicar à família e paciente pare que adquiram a medicação

d) administrar a medicaçãoficando o custo da mesma sob a responsabilidade do médico e família

17. Aosolictarumainterconsulta por outro médico de um paciente sob seus cuidados em regime hospitalar, qual omelhor procedimento?

a) solicitar por escrito e aguardar avaliação

b) solicitar a avaliação por telefone e apresentar o caso pessoalmente ao consultor

c) ligar e solicitar a avaliação aguardando o laudo do consultor

d) solicitar avaliação por escrito e apresentar o caso pessoalmente ao consultor

18. No caso de haver procedimento de forma incorreta, realizado por profissional não-médico, em regime de pré-hospitalar, o que fazer?

a) repreender no momento do ocorrido

b) afastar o profissional responsável pelo ocorrido e solictarà à chefia imediatamente sua substituição c) comunicar ofato à chefia e aguardar medidas cabíveis

d)salientar oerro no momento, ensinar o procedimento correto emanter o profissional responsável peloerro sobobservação

19. Um paciente encontra-se em tratamento para Hipertensão Arterial Sistêmica (HAS) com esquema tríplice de drogas. Uma das drogas, em sua opinião e experiência, pode trazer muitos efeitos colaterais, e você é quem está agora cuidando do paciente. Você tem o desejo de mudar aquela medicação. Qual seria a melhor forma de fazê-lo?

a) atterar a prescrição anterior salientando o porquê e explicar ao paciente o que acha que poderia acontecer b) fazer nova prescrição e explicar posologia

c) alterar a prescrição, explicar ao paciente e informar ao médico que fez a prescrição anterior

d) salientar a questão em discussão com o médico que fez prescrição anterior sem alterar medicação até discutir a questão

20. Emumambulatório de Hepatologia, hádois pacientes do sexo masculino, comidades aproximadas, portadores de hepatopatia crônica e irreversível, em fase avançada, com prognóstico similar, candidatos a transplante hepático, sendo umalcoolista e o outro não. Há umfigado disponivel em tal hospital, e ambos apresentaram perfil de histocompatibilidade aceitável para com o órgão. Qual seria sua conduta?

a) preterir o paciente alcoolista am prol do outro, pois o alcoolismo determina pior prognóstico

b) preterir o paciente não-alcoolista em prol do alcoolista, pois o alcoolismo constitui problema social maisimportante

c) avaliar as possibilidades de sobrevida pós-transplante dos pacientes e, então, encaminhar o mais apto d) encaminhar ambos para um serviço onde haja dois órgãos à disposição

21. Em um ambulatório de doenças sexualmente transmissíveis, um paciente lhe revela ser homossexual e manter relações que o próprio paciente considera como promíscuas. O médico que o atende, por outro lado, é católico fervoroso, e condena veementemente tal conduta. O paciente apresenta sintomas sugestivos de imunodepressão e grande ansiedade em relação a seu estado. Qual seria a melhor conduta? a) recusar-se a continuar o atendimento, pois o estilo de vida do paciente é responsável por sua doença b) realizar normalmente a anamnese, porém evitar exames físicos, por precaução c) atender normalmente o paciente, solictar os exames necessários e orientá-lo d) encaminhá-lo para profissional mais bem preparado para lidar com tais casos, sem consulta prévia

22. Após uma rebelião em um presídio, um detento é gravemente ferido. Chegando ao pronto-socorro do hospital mais próximo, há dois plantonistas disponíveis. O primeiro plantonista prefere esperar que outro plantonistaatenda o detento, pois, segundo o próprio, não acha que se devaatender estes casos. O segundo plantonista atende, após alguns minutos, o detento. A atitude do primeiro plantonista, a seu ver, foi:

a) adequada, pois médicos não são obrigados a atender pacientes indesejáveis

b) inaceitável, pois é dever clássico e inviolável do médico a preservação da vida humana

c) inaceitável, pois o primeiro plantonista não sabia àquela altura quem havia iniciado a rebelião d) adequada, pois o paciente era um detento perigoso e representava risco para a vida do médico

23. Durante a desocupação de uma propriedade rural invadida por trabalhadores rurais sem-terra, ocorreu conflito entre estes e aforça policial. Um dos trabalhadores sem-terra foi ferido, sendo encaminhado para o setor de urgência e emergência do hospital geral da cidade mais próxima. Lá, foi constatada anecessidade de cirurgia de emergência. Havia apenas dois cirurgiôes disponíveis na região, um em uma cidade a $20 \mathrm{~km}$ de distância, e o outro $50 \mathrm{~km}$. O primeiro cirurgião contatado, proprietário rural, que se expressava como adversário ferrenho do Movimento dos Trabalhadores Rurais Sem-Terra, inclusive na imprensa local, encontrava-se desocupado no momento. Em sua opinião, ele:

a) deveria encaminhar-se para o hospital e atender o paciente da melhor maneira possivel, mesmo sendo ideologicamente contrário ao mesmo

b) poderia protelar o atendimento e sugerir que se contatasse 0 outro, pois não se sentiria bem operando tal paciente

c) deveria encaminhar-se para o hospital e atender o paciente da maneira que julgasse adequada para o paciente, mesmo que esta não fosse a melhor possivel

d) poderia simplesmente recusar-se a atendê-lo

24. Paciente de 80 anos, portador de demência senil, com alto grau de dependência sofre fratura de colo de fêmur. Qual a conduta mais adequada?

a) colocar prótese cirurgicamente, pois a mesma é indicada para o tratamento de todos os pacientes com fratura de fêmur

b) não colocar prótese, pois o paciente não está em idade economicamente ativa

c) após avaliação, dado o prognóstico, levar em consideração a opçãoo por condutas alternativas não-cirúrgicas

d) avisar a familia e, caso esta queira, colocar a prótese independentemente dos riscos

25. Paciente de 35 anos, chega ao pronto-socorro emagrecido e levemente dispnéico, com monilíase bucal. Já é a oitava vez que o paciente procura o PS. Mal o examinam e sugere-se que procure UBS para exame de HIV. Em sua opinião, a conduta:

a) está correta, pois o quadro clínico é muito sugestivo de AIDS

b) está errada, pois os médicos do PS não o examinaram adequadamente

c) está certa, pois o HIV tem alta contagiosidade e o profissional de saúde deve se resguardar

d) está errada, pois o médico não pode sugerir que um paciente faça teste de HIV

\section{CONSIDERAÇÕES FINAIS}

Você achou interessante este questionário?

Você se sentiu incentivado a obter informações sobre os temas abordados?

Você acredita que atua de forma ética na maior parte das situações?

$\begin{array}{ll}\text { ( ) Sim } & \text { ( ) Não } \\ \text { ( ) } \operatorname{Sim} & \text { ( )Não } \\ \text { ( ) } \operatorname{Sim} & \text { ( ) Não }\end{array}$




\section{ANEXO - QUESTIONÁRIO 2}

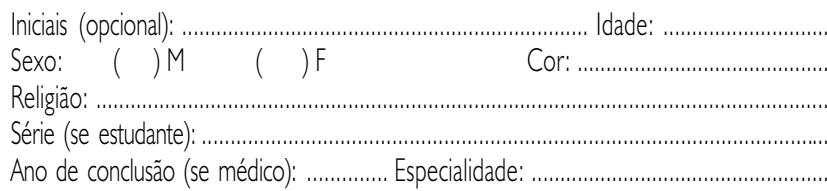

\section{QUESTÖES}

1. Paciente precisa de medicações para controle de sua doença. Tais medicações são disponíveis na rede pública, mas a demanda por elas é maior que o estoque. Por vezes, 0 paciente foi até a farmácia de sua instituição e não conseguiu o medicamento. Você, desconfiado, indaga ao funcionário responsável e este revela que alguns outros funcionários dão privilégios a determinados pacientes conhecidos. Você:

a) orienta o paciente a conseguir medicamentos em drogarias particulares

b) procura o responsável geral e solicita as medicações para seu paciente

c) denuncia a irregularidade às autoridades competentes

d) orienta-o a procurar outro serviço

2. Paciente em acompanhamento para determinada doença sexualmente transmissível em seu ambulatório, onde todos os outros médicos de sua especialidade se encontram em férias. Há dois anos, você já havia tratado a paciente devido a problema semelhante, tendo obtido na época cura completa da doença e orientado a paciente sobre como evitar novo contágio. Devido ao fato de a paciente ter novamente se contaminado:

a) você pode se recusar a atendê-la, pois ela não segue suas orientações

b) você nunca pode se recusar a atendê-la

c) você deve atendê-la nesta situação, pois é pertinente insistir

d) você não deve atendê-la, pois suas orientaçōes se mostraram ineficazes

3. Criança de três anos de idade em cetoacidose diabética e pneumonia necessita de internação para tratamento hospitalar. A mãe acha que a criança está bem e tenta levá-la embora, contra as orientações da equipe médica. Você:

a) não libera a criança e solicta suspensão temporária do pátrio-poder

b) libera a criança, pois o responsável tem o direito de tomar tal decisão

c) não libera a criança e solicita perda permanente da guarda, por considerar tal mãe incapaz de cuidar de seu filho

d) libera a criança e a orienta a procurar atendimento ambulatorial com urgência

4. Um indivíduo que já foi atendido váras vezes e faz acompanhamento em determinado hospital vai mudar-se para outro Estado. Dirige-se a tal serviço e solicita a entrega de seu prontuário médico para levá-lo consigo. A conduta correta do responsável pelos prontuários é:

a) não entregar o prontuário, pois o mesmo é de propriedade do hospital

b) entregar o prontuário, pois o mesmo pertence ao paciente

c) entregar o prontuário apenas após consultar o Conselho Regional de Medicina

d) não entregar o prontuário, pois as informações ali contidas são sigglosas

5. Em um ambulatório de Gastroenterologia Cirúrgica de um hospital-escola, um paciente que necessita de uma cirurgia eletiva pergunta a determinado cirurgião se ele pode operálo em outro hospital, em regime particular. A conduta mais ética, a seu ver, é:

a) entregar cartão com telefone de contato para o paciente

b) discutir no próprio ambulatório agendamento e planos de pagamento

c) orientar o paciente a procurar tal informação no outro hospital ou em seu consultório

d) recusar-se a prestar qualquer informação

6. Você tem dois procedimentos diagnósticos para determinada doença. Um é considerado padrão-ouro, porém é altamente custoso. $\mathrm{O}$ outro é razoavelmente satisfatório e apresenta custo bem menor. Você:

a) solicita o exame padrão-ouro para todos os pacientes

b) solicita o exame padrão-ouro apenas para pacientes particulares

c) discute com o paciente os dois procedimento e toma decisão em conjunto

d) solicita apenas o procedimento razoável, uma vez que a maioria não dispõe de recursos para 0 outro
7. Você é radiologista e um amigo próximo the relata estar fazendo um tratamento para hanseníase. Tal amigo the diz que está incomodado com tal situação e the pede informações acerca da doenç̧a, sendo que você não dispõe de informações atuais. A atitude mais adequada, em sua opinião:

a) discutir o caso com colegas, revelando a identidade do paciente

b) orientá-lo a procurar um colega mais atualizado

c) orientá-lo de acordo com as informaçōes de que você dispõe, mesmo sendo estas desatualizadas

d) recusar-se a discutir o caso

8. Garoto de 15 anos revela ao médico em consulta pedíátrica que foi sexualmente assediado por seu padrasto e pede sigilo acerca do caso, por medo de represálias. Você: a) guarda sigilo da situação em quaisquer condições

b) conta o fato à mãe do paciente

c) denuncia o padrasto à polícia

d) procura o Conselho Tutelar e expõe o caso, solicitando investigacãa

9. Paciente é avaliado por você, que faz diagnóstico de hanseníase. Ela trabalha numa lanchonete e pede sigilo por temer uma demissão. Você:

a) atende $o$ pedido e orienta cuidados de higiene

b) comunica ao proprietário da lanchonete

c) comunica o fato à Vigilância Sanitária

d) acompanha a paciente e, se ela se mantiver bem, mantém sigilo

10. Você é ginecologista e um marido de determinada paciente Ihe liga, informando ter contráído uma doença sexualmente transmissível em relação extraconjugal. Solicita que você não conte à esposa que tal doença tem caráter sexualmente transmissível. Sua paciente chega para consulta com sintomas sugestivos e bastante desconfiada, e the questiona se seus sintomas podem ser devidos a uma DST. Você:

a) diz que não se devem a uma DST, devido ao sigilo solicitado pelo marido

b) diz que a doença pode ser sexualmente transmissível

c) muda de assunto

d) diz que a doença é sexualmente transmissível e culpa o marido por tais sintomas

11. Paciente psicótico de 25 anos revela em ambulatório a você, psiquiatra, intenções homicidas acerca de um vizinho e the pede sigilo absoluto sobre 0 assunto. Você:

a) comunica o fato à familia do paciente

b) comunica o fato à polícia

c) comunica o fato à direção do hospital

d) guarda sigilo da informação

12. Em um ambulatório de Ortopedia, você tem dois pacientes de mesma idade aguardando cirurgia para correção de uma anormalidade na mão, um devido a acidente de trabalho e o outro devido a acidente de trânsito. Tal paciente lhe confessou que estava embriagado ao volante quando o acidente ocorreu. Qual paciente deve ser operado primeiro, em sua opinião:

a) o paciente vítima de acidente de trânsito, porque tal problema tem maior importância epidemiológica

b) o paciente vítima de acidente de trabalho, porque não teve culpa por seu problema

c) o paciente vítima de acidente de trabalho, porque os custos sempre serão pagos pelo patrão do paciente

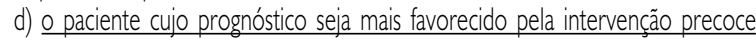

13. Você precisa encaminhar um paciente ao cardiologista, mas o único que atende pelo SUS na cidade, apesar de competente, é de partido poltico oposto ao seu. Você:

a) encaminha o paciente para cidade vizinha

b) solicita que o paciente faça consulta particular e indica outro médico

c) encaminha para este cardiologista sem carta de encaminhamento

d) manda encaminhamento por escrito para este cardiologista e solicita contra-referência 
14. Sr. Y, 64 anos, portador de uma neoplasia maligna sob controle e coronariopata com insuficiência cardíaca congestiva, após três infartos miocárdicos. Paciente consciente, não deseja se submeter a nenhuma intervenção. Sente que já viveu o suficiente e deseja falecer em paz. Em determinado dia, sente dores precordiais, onde é indicado cateterismo. $\mathrm{O}$ médico é informado dos fatos e o sr. Y mantém seu pedido. $\mathrm{O}$ que o médico deveria fazer?

a) realizar o cateterismo sob quaisquer condições, pois se trata de uma emergência

b) tentar convencer o sr. Y a submeter-se ao procedimento e, caso ele não aceite, contatar a familia

c) contatar a família e insistir para que esta permita a realização do procedimento

d) administrar sintomáticos e observar evolução, respeitando o pedido do sr. Y

15. E.J.G., 12 anos, portador de hemofilia A leve, necessita fazer cirurgia de urgência. Os pais relatam ser contra qualquer tipo de transfusão de sangue ou derivados por motivos religiosos. O cirurgião discute com o hematologista, que orienta fazer "concentrado de fator VIII" para evitar sangramentos em excesso. Qual a melhor conduta?

a) fazer a cirurgia e, se necessário, transfundir mesmo contra a vontade dos pais, avisando apenas a direção do hospital

b) transfundir o "concentrado" e após fazer cirurgia, mesmo correndo o risco de ser processado

c) recusar-se a fazer a cirurgia

d) contactar o juiz de plantão e avisar do caso aguardando resolução

16. Paciente necessita fazer procedimento que o convênio não fornece. $O$ que deve o médico fazer?

a) Informar a necessidade do procedimento ao convênio

b) Comunicar o fato ao paciente e realizar laudo demonstrando a necessidade do procedimento ao convênio

c) Comunicar à família e ao paciente para que realizem o procedimento por conta própria ou através do SUS

d) Realiza o procedimento ficando o custo da mesmo sob a responsabilidade do médico e da família

17. Você é clínico geral e o departamento de ginecologia solicita sua avaliação para uma paciente. Você:

a) Informa a necessidade do procedimento ao convênio

a) faz avaliaçãa e comunica sua opinião ao médico plantonista

b) avalia e comunica ao médico que solicitou sua avaliação

c) escreve sua avaliação no prontuário da paciente e comunica ao médico que solicitou sua avaliação

d) aguarda que o médico solicitante o procure para discutir o caso

18. Centro de referência recebe criança com quadro de neurotuberculose. Pela anamnese, o pai da criança estava em tratamento para tuberculose em fase bacilffera, a mãe procurou pediatra, que orientou não haver necessidade de realização de quimioprofilaxia para a criança. Você, ciente do erro do pediatra, ao ser questionado, o que faria?

a) por motivos éticos se recusaria a comentar a conduta do outro profissional

b) explicaria qual seria a conduta correta a ter sido tomada, não explicitando a responsabilidade do colega por ser algo muito especifico da especialidade de Infectologia

c) Apenas orientaria a família a procurar outras fontes de informação

d) Enfatizaria o erro do pediatra, expondo qual deveria ser a conduta correta

19. Paciente em tratamento para diabetes com esquema de drogas que em seu modo de pensar pode trazer efeitos colaterais importantes. Você deseja mudar a medicação deste paciente que agora passará a ficar sob seus cuidados. Qual seria a forma correta de fazer isso?

a) alterar a prescrição anterior salientando o porquê

b) fazer nova prescrição explicando como deve ser a posologia correta

c) alterar a prescrição, explicar ao paciente e informar o médico que fez a prescrição anterior

d) discutir com o médico que fez a prescrição anterior sem alterar a medicação antes
20. Instituto de Infectologia possui uma vaga disponível na UTI e na enfermaria deste há duas pacientes internadas que necessitam desta vaga. Ambas têm a mesma idade e são do sexo feminino, a Ia, é "prostituta" com AIDS, e a $2^{\mathrm{a}}$ contraiu a infecçãa do manido. Qual o melhor procedimento? a) esperar outra vaga surgir e após encaminhar as duas

b) escolher a $2^{\mathrm{a}}$, pois a I tem prognóstico desfavorável

c) avaliar ambas e escolher a que tem mais chance de sobreviver

d) mandar a que corre maior risco de morte

21. Paciente, em um ambulatório de fertilização, revela ter praticado três abortos anteriormente, agora deseja engravidar. O médico que a atende é publicamente contrário a práticas abortivas. Qual procedimento o médico deve adotar?

a) explicar que infertilidade é culpa dela ter praticado abortamentos e criticá-la

b) atendê-la como cliente comum e proceder conforme rotina

c) recusar-se a continuar o tratamento por motivos pessoais, orientando outro profissional, mesmo que não haja outro na região

d) fazer logo a inseminação para se ver livre daquela situação

22. Durante passeata organizada por grupo de defesa dos direitos dos homossexuais, houve conflito entre estes e um grupo de extremistas religiosos, ocorrendo ferimentos graves em um dos manifestantes homossexuais, que necessita de assistência neurocirúrgica. Há apenas dois neurocirurgiões na cidade, e um deles encontra-se em ato cirúrgico. $O$ outro é membro da organização religiosa da qual faziam parte os extremistas envolvidos no conflito. Tal neurocirurgião recusa-se a atender tal paciente, orientando os plantonistas a aguardarem o segundo cirurgião. Após o término do ato cirúrgico, este se dirige e atende o paciente, que é operado e vai a óbito no dia seguinte. A seu ver, a conduta do primeiro neurocirurgião foi:

a) adequada, pois não era sua obrigação atendê-lo, uma vez que não estava de plantão

b) inadequada, pois estava caracterizada uma situação de emergência

c) adequada, pois ele não teria condições psicológicas de atendê-lo adequadamente

d) inadequada, pois o médico não pode se recusar a atender um paciente em quaisquer condições

23. Durante rebelião em instituição de contenção de menores infratores, houve um conflito entre estes e a força policial, ocorrendo ferimentos graves em um menor e algumas escoriações em um policial. Você é o plantonista do hospital que recebe estes indivíduos. Você atende primeiro:

a) o policial, pois este estava cumprindo seu dever

b) o menor infrator, pois sempre devem ser priorizados os pacientes mais jovens

c) aquele cujos ferimentos necessitem de auxilio mais precoce

d) aquele cujos ferimentos sejam mais leves, pois a possibilidade de sobrevida é maior

24. Você recebe um paciente de 85 anos, com diagnóstico de câncer de pulmão, já com metástases à distância (estádio IV). O paciente encontra-se consciente, inclusive de seu diagnóstico. Dentre as poucas alternativas quimioterápicas disponíveis em seu serviço, há um medicamento com melhor eficiência que os demais no controle da neoplasia, que possui, porém efeitos colaterais que provocam comprovadamente queda na qualidade de vida do paciente, especialmente em pacientes idosos. Você:

a) administra tal medicamento em qualquer situação

b) discute com o paciente sobre as alternativas e decide em conjunto

c) discute apenas com a família sobre as alternativas e decide em conjunto

d) não administra tal medicamento em hipótese alguma

25. Mulher de 26 anos vai a uma UBS com queixa de corrimento vaginal de odor fétido e cor amarelada. O médico não a examina e prescreve medicamentos que julga adequados, por julgar a queixa sugestiva o suficiente. A seu ver, a conduta está:

a) correta, pois o quadro clínico descrito é muito sugestivo

b) errada, pois ele deveria ter solicitado exames complementares

c) certa, pois o odor fétido pode ser considerado um empecilho ao exame físico

d) errada, pois ele deveria efetuar o exame ginecológico

\section{CONSIDERAÇÕES FINAIS}

Você achou interessante este questionário?（） Sim（） Não

Você se sentiu incentivado a obter informações sobre os temas abordados? ( ) Sim ( ) Não Você acredita que atua de forma ética na maior parte das situações? ( ) Sim ( ) Não 


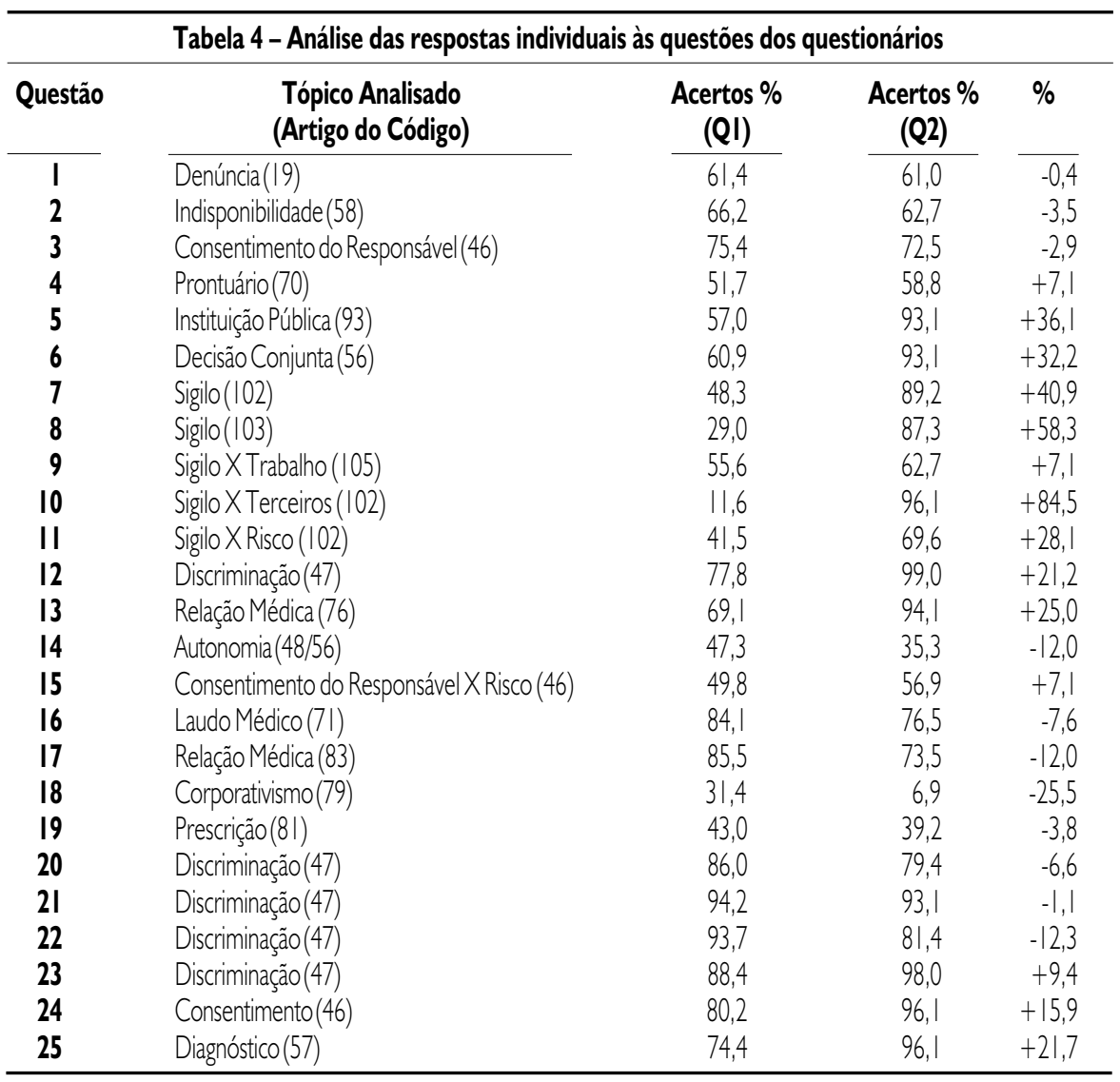

Tabela 5 - Diferença entre média de acertos nos questionários por método de ensino

\begin{tabular}{lcc}
\hline & N & Média de acertos (DP) \\
Método Tradicional & 51 & $17,15(2,66)$ \\
Aprendizado Baseado em Problemas & 230 & $\mid 6,51(3,14)$ \\
\hline
\end{tabular}

$p>0,05$

b) Sigilo Médico - Artigos 102 a 105. Como bem foi dito por Porthes, "não há medicina sem confidências, não há confidências sem confiança e não há confiança sem segredo", reiterando o raciocínio de Santo Agostinho ("o que sei por confissão, sei o menos de que aquilo que nunca soube") $)^{4}$. De um lado, tais princípios nortearam a corrente absolutista do segredo médico, por demais intransigente, em oposição à corrente abolicionista, por demais leviana. Hoje, preconiza-se a corrente eclética ("in medio virtus"), baseada na teoria utilitarista de Benthan, criador da Deontologia, que considera que "bom é o útil ou vantajoso para o maior número de homens" ${ }^{16}$. O crime de quebra de sigilo está descaracterizado quando sua revelação fundamenta-se na justa causa, no estrito cumprimento do dever legal e na autorização expressa do paciente ${ }^{14}$.

c) Autonomia - Artigos 48/56. Autonomia (do grego "autos - eu" e "nomos - lei") significa autogoverno, autodeterminação da pessoa de tomar decisões que afetem sua vida, sua saúde, sua integridade físico-psíquica, suas relações sociais. Refere-se à capacidade de o ser humano decidir o que é "bom", ou o que é seu "bem-estar" I5. Com o exerćício da autonomia, o homem tem uma participação mais responsável na vida, sendo crítico e participativo, incluindo a participação em tratamentos médicos, podendo ser livre para decidir e opinar no que diz respeito à sua maneira de viver ${ }^{17}$. d) Consentimento do Responsável - Artigo 46. Tal tópico apresentou um resultado curioso. Por um lado, quando era confrontado o não consentimento do responsável legal devido à déficit sócio-cultural, o índice de acertos foi alto. Por outro lado, quando o motivo do não-consentimento eram fatores religiosos, não se observou o mesmo. Conforme o parecer do Conselho Regional de Medicina de São Paulo, de 1974, na situaçãa em que o paciente menor de idade, na qual os pais negam autorização para transfusão de sangue ou hemoderivados, o médico recorrerá à autoridade judiciária, exigindo uma decisão que preserve sua posição (...) "Podem os pais em determinadas e raras ocasiões privar seus filhos de algumas liberdades, porém em nenhum momento podem eles tirar-thes 0 direito de viver" ${ }^{\prime \prime}$.

e) Corporativismo - Artigo 79. Como bem disseca França, "quem não respeita (os limites de sua capacidade) é imprudente. Se um médico desatualiza-se e comete sucessivamente erros no desempenho de seu ofício, não se poderá chamar a isso de imperícia, mas, tão-somente de negligência, pois é princípio elementar que todo profissional deve procurar estar informado dos progressos relativos ao seu mister. Essa necessidade não é apenas de ordem moral, mas uma obrigação de todo homem de ciência"14. Convém frisar, a lealdade elemento fundamental ao comportamento ético, segundo Aristóteles, definida como a "franqueza, a sinceridade, a coragem da crítica de corpo presente. É desleal aquele que oculta a verdade, que é covarde e fala mal por de trás. Não é leal aquele que permite o colega persistir no erro, prejudicando outrem e a própria reputação"16.

f) Prescrição Médica - Artigo 81. Conforme dita Alcântara, "um medicamento só será substituído mediante prévia autorização de quem fez a prescrição"16.

Observaram-se grandes dificuldades à execução do projeto, em especial, a baixa adesão, observada em todos os grupos avaliados, principalmente na segunda fase, e generalizadamente entre os docentes, mesmo com a garantia de sigilo que o questionário provia. Isto talvez se deva ao fato de que os mesmos se encontravam sob o papel de avaliados e não de avaliadores, o que pode ter gerado insegurança ou desinteresse. 
Ao final do questionário quando inqueridos acerca da aprovação do questionário houve $92 \%$ de aprovação, $5 \%$ não aprovaram e $3 \%$ não responderam no primeiro questionário e no segundo, 95\% aprovaram, 2\% não aprovaram e $3 \%$ não responderam.

\section{Conclusão}

Quando sujeitos à avaliação, uma grande parte dos professores da área médica, sentem-se acuados e constrangidos por terem seus conhecimentos éticos e deontológicos avaliados, vide a baixa adesão à resposta aos questionários, num universo de aproximadamente 220 docentes.

Nosso estudo não mostrou diferença estatisticamente significante na apreensão de conceitos éticos e deontológicos quando 0 tipo de modelo pedagógico foi testado (ABP $X$ Tradicional).

Demonstrou-se também a necessidade de reforço, em particular em nossa instituição, na atenção aos tópicos com desempenho mais deficitário (o acesso ao prontuário médico, o sigilo médico - tanto individual quanto em relação a risco, a autonomia do paciente, o consentimento do responsável, o corporativismo e a prescrição médica).

$O$ estudo sugere fortemente que quanto antes se introduzir no currículo médico a reflexão sobre aspectos éticos e deontológicos, maior será a possibilidade da apreensão e reflexão sobre o tema pelos jovens acadêmicos, e esta parece ser a variável mais importante visando a melhoria do ensino-aprendizado nesta área. Da mesma forma, isto aponta para um ensino de ética pulverizado, e desta forma passível de ser discutido por vários profissionais em momentos variados do curso, e não mais concentrado numa única disciplina de Ética Médica.

Que a própria estratégia de fomento de bolsas de pesquisa na área, desenvolvida pelo CRM, parece ser muito efetiva, criando um clima muito favorecedor a este aprendizado, dado que ao menos em nossa Faculdade, este tema foi colocado na ordem do dia, e com oito bolsas concedidas, temos ao menos trinta pessoas entre docentes e acadêmicos diretamente envolvido com o tema, e praticamente toda a comunidade envolvida na resposta aos questionários, por vezes a mais do que um. Isto é objetivado pelo aumento do acerto, após intervalo de meses, entre os dois questionários.
O ensino da Ética não pode, sob hipótese alguma, estar dissociado de seu conteúdo filosófico, sociológico e cultural, bem como de seu compromisso com a conjuntura sóciopolítica, uma vez que se liga a pontos intrinsecamente controversos nos quais, por vezes, o profissional apresenta dificuldades técnicas que poderiam ser minoradas caso a formação médica conseguisse apontar mais caminhos.

\section{Agradecimentos}

Este trabalho foi desenvolvido por bolsa de estudo cedido pelo Conselho Regional de Medicina do Estado de São Paulo.

\section{Conflito de interesse: não há.}

\section{SUMMARY}

ACQUISITION OF SKILLS IN MEDICAL ETHICS ON THE SMALL GROUP LEARNING-TEACHING METHOD. Comparing tHE PROBLEM BASED LEARN WITH A TRADITIONAL MODEL.

BACKGROUND. Aimingto evaluate the acquisition of skills on Medical Ethics among medical students from Marilia Medical School, some of them from the small group learning-teaching method, others from traditional teaching method.

METHODS. A prospective analytical study was done based on the application of questionnaires about general themes on Ethics, at two different times.

RESULTS. There weren't significant differences on the skills' acquisition between the two methods. Students from late graduation years showed a significantly better performance than those from early years. The themes that presented worse results were medical secret, legal responsible consent, patient autonomy, medica/ prescription, medical handbook and corporative feeling in the presence of medicalmistake.

CONCLUSION. The mostimportant difference between the groups was not the pedagogical pattern but the exposition time to the theme. $P B L$ gives the chance to distribute the theme in differents situations accelerating the acquisition of knowledge in Medical Ethics. It was realized that a revitalization on Medical Ethics teaching is necessary at our institution, aiming a better integration with the socio-economical situation in our country. [Rev Assoc Med Bras 2004; 50(2): |33-4|]

KEY WORDS: Medical Ethics. Teaching. Questionnaire.

\section{REFERÊNCIAS}

I. Zajdsznajer L. É a ética uma ciência?. In: Assad JE, coordenador. Desafios éticos. Brasília: Conselho Federal de Medicina; 1993. Cap I, p. I5-20.

2. Cohen C, Segre M. Breve discurso sobre valores, moral, eticidade e etica. Bioetica 1994; 2:19-24.

3. Costa FAB. O novo código de ética medica. Brasília Med 1987; 24:31.

4. Hossne WS, Hossne RS. Opinião do estudante de medicina sobre algumas questões bioéticas. Bioética 1998; $6: 127-33$

5. Barchifontaine CP, Pessini L, Rover A. Bioética e saúde. São Paulo: Cedas; 1989.

6. Green MJ, Mitchell G, Stocking CB, Cassel CK, Siegler M. Do actions reported by physicians in training conflict with consensus guidelines on ethics? Arch Intern Med 1996; I 56:298-304.

7. Hayley DC, Cassel CK, Snyder L, Rudberg $M A$. Ethical and legal issues in nursing home care. Arch Intern Med 1996; 156:249-56.

8. Lima DF. Aspectos éticos e médico-legais em ginecologia e obstetrícia. Acta Méd 1997; 43:183-95.

9. Passos ES. Tendências da ética profissional na modernidade. Rev Bras Enferm 1993; 46:56-62.

10. Pereira Neto AF, Rocha SLA. Alem da norma: notas sobre dois códigos de ética medica brasileiros ( 93 | - 1988). Saúde Debate 1995; 46:23-7.

I I. Bissonette R, O'Shea RM, Horwitz M, Route CF. A data-generated basis for medical ethics education: categorizing issues experienced by students during clinical training. Acad Med 1995; 70: 1035-7.

12. Siqueira JE, Eisele RL. $O$ ensino da ética no curso de medicina. Rev Bras Educação Méd 2000; 24:22-30.

13. Sulmasy, D.P.; Duyer, M.; Marx, E. Knowledge, confidence, and attitudes regarding medical ethics: how do faculty and housestaff compare? Acad Med 1995; 70: 1038-40.

14. França GV. Direito médico. 6a ed. São Paulo: Byk; 1994.

15. Costa SIF, Garrafa V, Oselka GW. Iniciação à bioética. Brasília: CFM; 1998

16. Alcântara HR. Deontologia e dicetologia. São Paulo: Andrei; 1979.

17. Siqueira JE, Prota L, Zancanaro L, organizadores. Bioética: estudos e reflexões. Londrina: UEL; 2000.

Artigo recebido: 07/10/02

Aceito para publicação: 05/I I/03 